\title{
Secondary Flow Phenomena in an Axially Rotating Flow Passage with Sudden Expansion or Contraction*
}

\author{
SHUICHI TORII ${ }^{\mathrm{a}, \dagger}$ and WEN-JEI YANG ${ }^{\mathrm{b}}$ \\ ${ }^{a}$ Department of Mechanical Engineering, Kagoshima University, 1-21-40 Korimoto, Kagoshima 890, Japan; ${ }^{\mathrm{b}}$ Department of \\ Mechanical Engineering and Applied Mechanics, University of Michigan, Ann Arbor, MI 48109, USA
}

(Received 24 April 1998; In final form 9 June 1998)

\begin{abstract}
This paper investigates rotational effects on secondary flow in rotating flow passages with sudden expansion or contraction. Consideration is given to laminar flow. The governing boundary-layer equations are discretized by means of a finite-difference technique and numerically solved to determine the distributions of velocity vector under the appropriate boundary conditions. The Reynolds number $(\mathrm{Re})$ and rotation rate are varied to determine their effects on the formation of secondary flows. It is disclosed from the study that: (i) when laminar flow is introduced into an axially rotating pipe with expansion, the stretch of the secondary flow zone is amplified with an increase in the rotation rate and $R e$, and (ii) in contrast, for axially rotating pipe flows with contraction, the secondary flow region is somewhat suppressed due to pipe rotation, and the change is slightly affected by the rotation rate and $\mathrm{Re}$. Results may find applications in automotive and rotating hydraulic transmission lines.
\end{abstract}

Keywords: Secondary flow, Rotational effect, Sudden contraction/expansion of flow passage, Numerical analysis

\section{INTRODUCTION}

The convective heat transfer in swirling flows is often encountered in chemical and mechanical mixing and separation devices, electrical and turbo-machinery, combustion chambers, pollution control devices, swirl nozzles, rocketry, and fusion reactors. In these flow fields, the heat transport phenomena in connection with the flow are substantially influenced by the centrifugal force induced by the swirl. In other words, the transport phenomena of heat and momentum are suppressed or promoted by centrifugal force associated with the swirl.

The flow in an axially rotating pipe is related to flows such as the inlet part of fluid machinery, rotating heat exchangers and cooling systems of rotors. The effects of pipe rotation on flow have been studied by several investigators (for example, White, 1964, Nagib et al., 1971). Murakami and Kikuyama (1980) measured the velocity profile and hydraulic loss in a hydrodynamically

\footnotetext{
* This paper was originally presented at ISROMAC-7.

${ }^{\dagger}$ Corresponding author. Tel.: 099-285-8245. Fax: 099-285-8246. E-mail: torii@)mech.kagoshima-u.ac.jp.
} 
fully-developed flow region of a rotating pipe. It was disclosed that pipe rotation suppresses both turbulence and hydraulic loss and that the streamwise velocity profile is gradually deformed into a parabolic form with an increase in its speed. Kikuyama et al. (1983) calculated the variation of streamwise velocity profiles in the fully-developed region of the rotating pipe using a modified mixing length theory. Hirai and Takagi (1988) performed the experimental and theoretical study to determine the effects of pipe rotation on fluid flow and heat transfer in a thermally and hydrodynamically fullydeveloped flow region. Fluid flow and heat transfer characteristics in the thermally and hydrodynamically developing and fully-developed regions of an axially rotating pipe were investigated by Torii and Yang (1995a,b) using the existing $k-\varepsilon$ turbulence models in which they are modified to include the swirling effect.

Yamada and Imao (1980) and Kikuyama et al. (1983) measured the streamwise velocity and hydraulic loss in a saturated downstream region of an axially rotating pipe in which a fullydeveloped laminar flow was introduced. It was disclosed that the hydraulic loss and the flow instability are induced due to the pipe rotation and that as its speed increases, the streamwise velocity approaches the turbulent one. This trend is in prominent contrast to that of the turbulent swirling flow in a rotating pipe. Velocity profiles in the laminar developing region of a rotating pipe were analyzed by Lavan et al. (1969), Mizutani et al. (1987) and Imao et al. (1989).

In many practical engineering applications, the working fluid in the rotating machinery flows in passages with sudden expansion or contraction. In order to understand transport phenomena in such passages, it is necessary to investigate the fluid flow in the axially rotating passages with sudden expansion or contraction, because the separation region exists in the expansion or contraction region. A detailed information on the flow, heat and mass transfer in the separation region is of great importance for many engineering applications. To the authors' knowledge, there is no experimental data pertinent to flow characteristics such as the velocity distribution for the axially rotating pipe flow case. In contrast, numerical studies have been conducted to determine fluid flow induced by the axial rotation of the pipe with sudden expansion or contraction.

This paper treats the fluid transport phenomena in the axially rotating pipes with sudden expansion or contraction. Emphasis is placed on Reynolds number $(\mathrm{Re})$ and rotation rate on the formation of secondary flows. A numerical method is employed to determine velocity profiles.

\section{NUMERICAL ANALYSIS}

Consider a steady incompressible laminar flow through a pipe with sudden expansion or contraction, which rotates around the axis. The physical configuration and the cylindrical coordinate system are shown in Fig. 1. Under the assumption of constant fluid properties, the governing differential equations for mass and momentum can be expressed as:

Continuity equation:

$$
\frac{\partial U}{\partial x}+\frac{\partial V}{\partial r}+\frac{V}{r}=0 .
$$

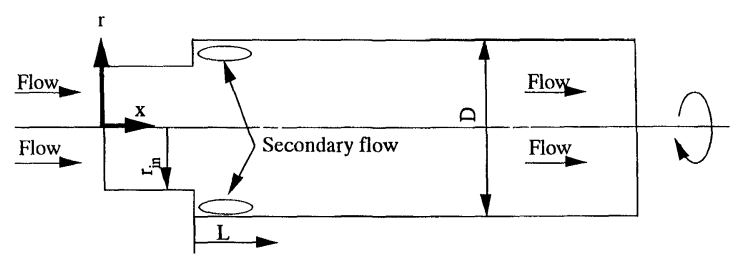

(a)

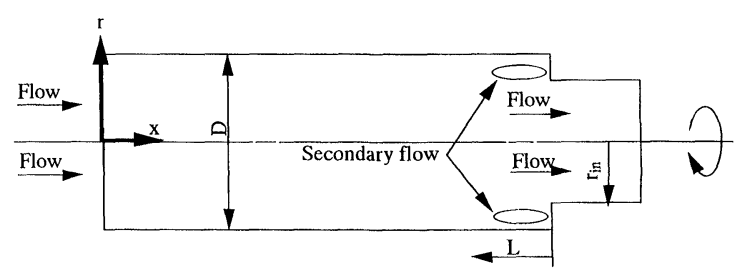

(b)

FIGURE 1 Schematic diagrams of axially rotating pipe flow systems and their coordinates: (a) expansion flow case and (b) contraction flow case. 


\section{Momentum equations:}

$x$ direction:

$$
\begin{aligned}
& U \frac{\partial U}{\partial x}+V \frac{\partial U}{\partial r} \\
& =-\frac{1}{\rho} \frac{\partial P}{\partial x}+\nu\left(\frac{\partial^{2} U}{\partial x^{2}}+\frac{\partial^{2} U}{\partial r^{2}}+\frac{1}{r} \frac{\partial U}{\partial r}\right)
\end{aligned}
$$

r direction:

$$
\begin{aligned}
& U \frac{\partial V}{\partial x}+V \frac{\partial V}{\partial r}-\frac{W^{2}}{r} \\
& =-\frac{1}{\rho} \frac{\partial P}{\partial r}+\nu\left(\frac{\partial^{2} V}{\partial x^{2}}+\frac{\partial^{2} V}{\partial r^{2}}+\frac{1}{r} \frac{\partial V}{\partial r}-\frac{V}{r^{2}}\right),
\end{aligned}
$$

$\theta$ direction:

$$
\begin{aligned}
& U \frac{\partial W}{\partial x}+V \frac{\partial W}{\partial r}+\frac{V W}{r} \\
& =\nu\left(\frac{\partial^{2} W}{\partial x^{2}}+\frac{\partial^{2} W}{\partial r^{2}}+\frac{1}{r} \frac{\partial W}{\partial r}-\frac{W}{r^{2}}\right)
\end{aligned}
$$

An isothermal laminar flow in the absence of rotation is assumed as the inlet condition. Only onehalf of the pipe cross-section is treated because of the symmetry in the fluid flow. The boundary conditions in the axially rotating pipe are specified as:

$$
\begin{aligned}
U & =V=0, \quad W=W_{\mathrm{w}} & \text { at wall, } \\
U & =U_{\mathrm{in}}, V=0, W=0 & \text { at the inlet, i.e. } x=0, \\
\frac{\partial U}{\partial r} & =0, \quad V=W=0 \quad & \text { at canter }(r=0) .
\end{aligned}
$$

Kikuyama et al. (1983) reported that when the laminar flow passes in an axially rotating pipe, a radial distribution of the tangential velocity shows a nearly forced vortex type profile, as

$$
\frac{W}{W_{\mathrm{w}}}=\left(\frac{r}{R}\right)
$$

The relationship, i.e., a linear radial profile of the tangential velocity is presented in the appendix. Kikuyama et al. (1983) found that neither Re nor rotation rate affects the radial profiles of the time-averaged tangential velocity at different axial locations. In the present study, Eq. (5) is employed to replace Eq. (4) in determining the tangential velocity, $W$, because it is effective in saving computation time.

In order to discretize the governing equations, the finite difference method proposed by Harlow and Welch (1965) and Hirt et al. (1975) is employed here. The system variables $P, U$, and $V$ are calculated with a staggered grid as proposed by Harlow and Welch (1965). Computation reveals only a small difference when the grid system is changed from $20 \times 200$ to $80 \times 800$. Hence, a grid system of $20 \times 200$ uniformly distributed nodal points is employed here to save computation time.

Numerical computation was performed on a Fujitsu personal computer (Pentium Pro CPU $200 \mathrm{MHz}$ ) which consumed up to $24 \mathrm{CPU}$ hours, using water as the working fluid $(\mathrm{Pr}=7.1)$. The parameters used in the present study are $\mathrm{Re}$ $\mathrm{Re}=250 \sim 2000$, rotation rates $N=0.0 \sim 2.0$ and radius ratio of expansion or contraction $r^{*}=0.75$.

\section{RESULTS AND DISCUSSION}

Figure 2(a)-(d), for $\operatorname{Re}=2000$, depicts the flow pattern over the $r-x$ cross-section in an axially rotating pipe with expansion at different rotation rates $N$, respectively. $N=0$ corresponds to no rotation case. An increase in $N$ implies an increase in the rotational speed at a given axial velocity. It is observed that a recirculation zone appears in the sudden expansion region of the flow passage and is extended with an increase in the velocity ratio of a rotating pipe to fluid flow, $N$. The change in the recirculation zone, i.e., the secondary flow zone due to pipe rotation becomes clearer in Fig. 3. Figure 3 illustrates the distance, $L$, of the expansion location to the reattachment point, as a function of $\mathrm{Re}$. One observes that with $\mathrm{Re}$ fixed, the reattachment point is moved in the downstream direction with an increase in $N$. Thus the streamwise movement of the reattachment point is ascribed to the pipe rotation. In other words, the recirculation zone is stretched in 


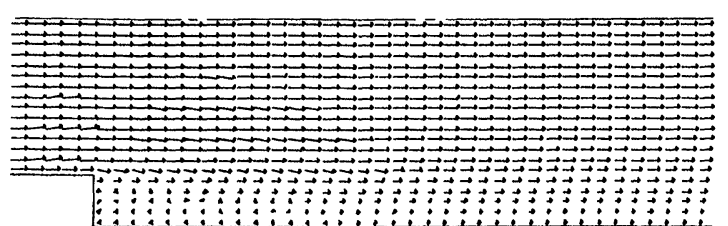

(a)

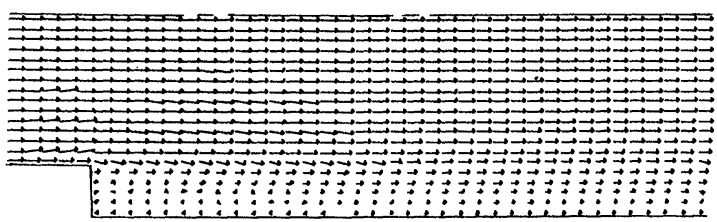

(b)

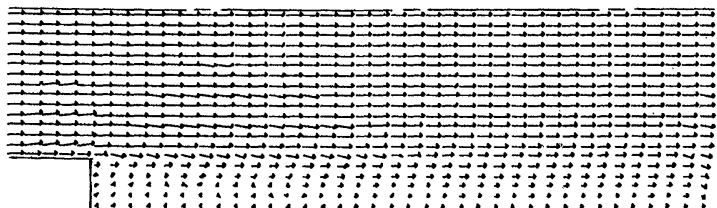

(c)

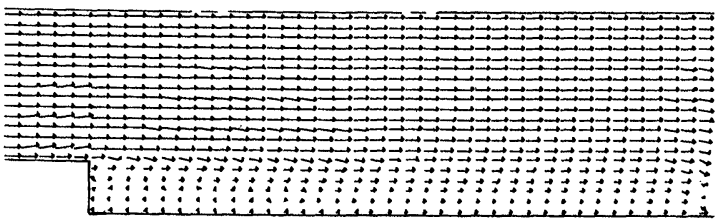

(d)

FIGURE 2 Velocity vector in axially rotating pipe with expansion at $\operatorname{Re}=2000$ : (a) $N=0$, (b) $N=0.5$, (c) $N=1.0$ and (d) $N=2.0$

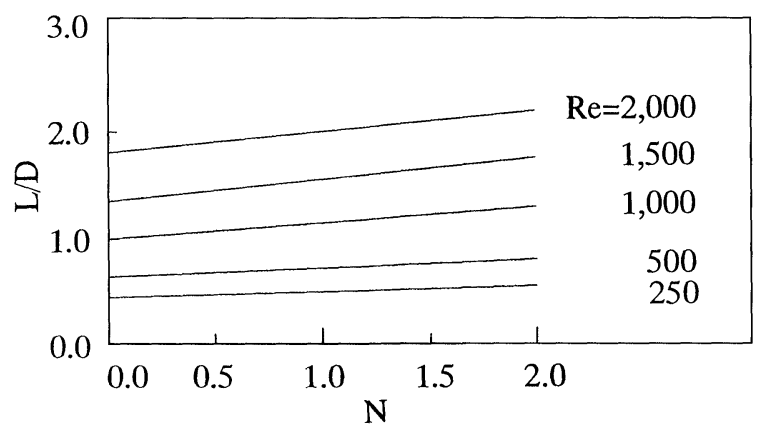

FIGURE 3 Effects of Re and rotation rate on $L$ for expansion flow case.

the streamwise direction due to the pipe rotation. As mentioned in the introduction, when laminar flow passes in an axially rotating pipe, an increase in its speed makes the streamwise velocity approach the turbulent one. It is postulated, therefore, that in

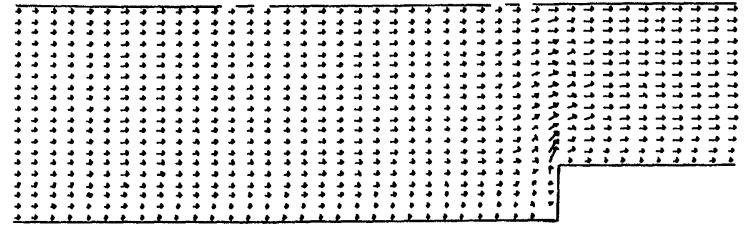

(a)

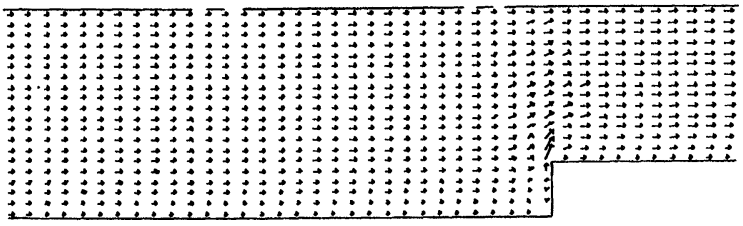

(b)

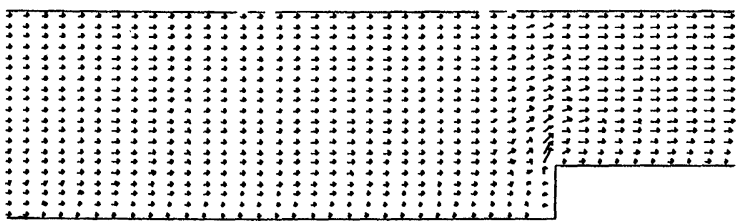

(c)

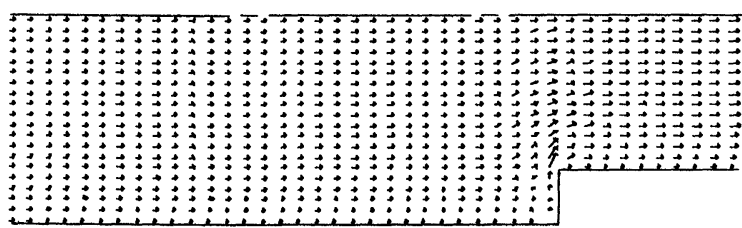

(d)

FIGURE 4 Velocity vector in axially rotating pipe with contraction at $\mathrm{Re}=2000$ : (a) $N=0$, (b) $N=0.5$, (c) $N=1.0$ and (d) $\mathrm{N}=2.0$.

the swirling case, the velocity in the vicinity of the wall is stimulated more than that in the absence of rotation, resulting in a stretch of the recirculartion zone. This tendency is found to be amplified with an increase in the Re, as seen in Fig. 3.

The flow pattern over the $r-x$ cross-section in an axially rotating pipe with contraction is depicted in Fig. 4 at $R e=2000$. Figure 4(a) - (d) corresponds to $N=0.0,0.5,1.0$ and 2.0, respectively. It is observed that secondary flows occur in the sudden contraction region of the flow passage and its zone is somewhat suppressed with an increase in the velocity ratio of a rotating pipe to fluid flow. Although there is the effect of pipe rotation on the formation of secondary flows, its change is only slight compared to the expansion flow case. The distance, $L$, of the separation point to the contraction location, as seen in Fig. 1(b), is illustrated in 


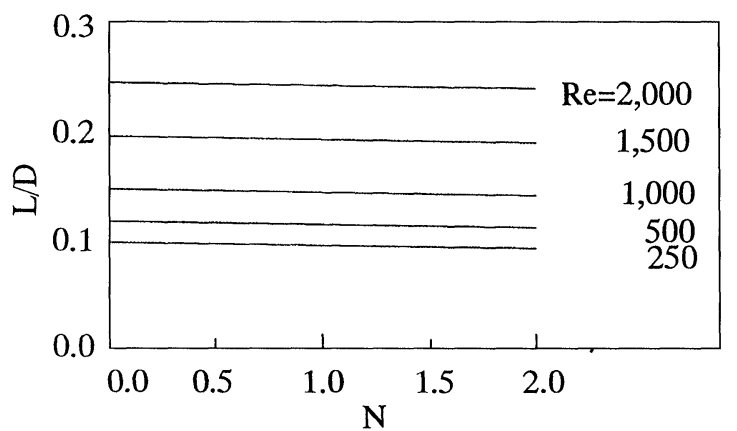

FIGURE 5 Effects of Re and rotation rate on $L$ for contraction flow case.

Fig. 5 in the same form as Fig. 3. Re is the parameter in the figure. It is observed that with Re fixed, the separation point is slightly moved toward the contraction section with an increase in $N$, i.e, the secondary flows formed in the contraction zone are suppressed due to pipe rotation. The effect of $\operatorname{Re}$ on $L$ is found to be minor with an increase in $N$.

In summary, when laminar flow is introduced into an axially rotating pipe with expansion, the secondary flow region is stretched by the axial rotation of the pipe. This trend is amplified with an increase in the rotation rate and $\mathrm{Re}$. In contrast, for the swirling flows with contraction, the secondary flow region is somewhat suppressed due to pipe rotation and there is only a slight effect of the rotation rate and the Re on the formation of the secondary flow.

\section{SUMMARY}

Numerical simulation has been employed to investigate the isothermal flow in an axially rotating pipe with expansion or contraction. Consideration is given to the influence of rotation ratio and Reynolds number on the formation of the secondary flows. The results are summarized as follows.

When laminar flow passes in an axially rotating pipe with expansion, the pipe rotation causes the stretch of the secondary flows formed in the expansion region. This trend is amplified with an increase in the rotation rate and Re. On the contrary, when the flow is introduced into the axially rotating pipe with contraction, the secondary flow region is somewhat suppressed due to pipe rotation, and the formation of the secondary flow is slightly affected by the rotation rate and $\mathrm{Re}$.

\section{NOMENCLATURE}

D $\quad$ pipe diameter, $\mathrm{m}$

$L \quad$ distance of the expansion location to the reattachment point or distance of the separation point to the contraction location, $\mathrm{m}$ rotation rate, $W_{\mathrm{w}} / U_{\mathrm{m}}$ time-averaged pressure, $\mathrm{Pa}$

Prandtl number radial coordinate, $m$ radius of pipe with expansion or contraction, $\mathrm{m}$ pipe diameter with expansion or contraction, $r_{\text {in }} / R$

\section{$R \quad$ pipe radius, $D / 2, \mathrm{~m}$}

Re Reynolds number, $U_{\mathrm{m}} D / \nu$

$U, V, W \quad$ time-averaged velocity components in axial, radial and tangential directions, respectively, $\mathrm{m} / \mathrm{s}$

$U_{\mathrm{m}} \quad$ axial mean velocity over tube cross-section at the inlet, $\mathrm{m} / \mathrm{s}$

$W_{\mathrm{w}} \quad$ tangential velocity on pipe wall, $\mathrm{m} / \mathrm{s}$ $x \quad$ axial coordinate, $\mathrm{m}$

\section{Greek Letters}

$\begin{array}{ll}\nu & \text { molecular viscosity, } \mathrm{m}^{2} / \mathrm{s} \\ \rho & \text { density of fluid, } \mathrm{kg} / \mathrm{m}^{3}\end{array}$

\section{Subscripts}

$\begin{array}{ll}\mathrm{m} & \text { mean } \\ \mathrm{w} & \text { wall }\end{array}$

\section{References}

Harlow, F.H. and Welch, E.J., 1965, Numerical calculation of time-dependent viscous incompressible flow of fluid with free surface, Phys. Fluids, 8, 2182-2189.

Hirt, C.W., Nichols, B.D. and Romero, N.C., 1975, SOLA-A numerical solution algorithm for transient fluid flows, LASL Report, LA-5852. 
Hirai, S. and Takagi, T., 1988, Prediction of heat transfer deterioration in turbulent swirling pipe flow, JSME Int. J., ser. II, 31(4), 694-700.

Imao, S., Zhang, Q. and Yamada, Y., 1989, The laminar flow in the developing region of a rotating pipe, JSME Int. J., ser. II, 32(3), 317-323

Kikuyama, K., Murakami, M., Nishibori, K. and Maeda, K. 1983 , Flow in an axially rotating pipe (a calculation of flow in the saturated region), Bulletin of the JSME, 26(214), 506-513.

Lavan, Z and Nielsen, H. and Fejer, A., 1969, Separation and flow reversal in swirling flows in circular ducts, Phy. Fluids, 12(9), 1747-1758.

Mizutani, M., Nishibori, K., Kikuyama, K. and Murakami, M. 1987, Inlet length for laminar flow in an axially rotating pipe, Turbomachinery, 15(3), 33-40.

Murakami, M. and Kikuyama, K., 1980, Turbulent flow in axially rotating pipes, J. Fluids Engineering, 102, 97-103.

Nagib, H.M., Lavan, Z., Fejer, A.A. and Wolf, L., 1971 Stability of pipe flow with superposed solid body rotation, Phys. Fluids, 14(4), 766-768.

Torii, S. and Yang, W.J., 1995a, Numerical prediction of fullydeveloped swirling flows in an rotating pipe by means of a modified $k-\varepsilon$ turbulence model, Int. J. Numerical Methods for Heat \& Fluid Flow, 5(2), 175-183.

Torii, S. and Yang, W.J., 1995b, A numerical analysis on flow and heat transfer in the entrance region of an axially rotating pipe, Int. J. Rotating Machinery, 2(2), 123-129.

White, A., 1964, Flow of a fluid in axially rotating pipe, $J$. Mechanical Engineering Science, 6(1), 47-54.

Yamada, Y. and Imao, S., 1980, Swirling flows in an axially rotating pipe, Trans, JSME, 46(409), B, 1662-1670 (in Japanese).

\section{APPENDIX}

Equations (4) is reduced as

$$
\frac{\partial}{\partial r}\left\{r^{3} \nu \frac{\partial(W / r)}{\partial r}\right\}=0
$$

Upon an integration, it yields

$$
r \frac{\partial(W / r)}{\partial r}=\frac{C^{\prime}}{r^{2} \nu}
$$

in which $C^{\prime}$ is an integration constant. Since the left term in Eq. (A-2) cannot be infinite at $r=0, C^{\prime}$ is set equal to zero, resulting in

$$
r \frac{\partial(W / r)}{\partial r}=0 .
$$

Thus, it is found that the rotating fluid moves as a rigid body. 


\section{ait \\ ENERGY MATERIALS}

M A N E Y publishing

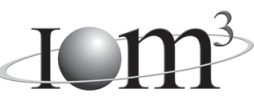

\section{Materials Science \& Engineering for Energy Systems}

Maney Publishing on behalf of the Institute of Materials, Minerals and Mining

The Institute of Materials, Minerals \& Mining

Economic and environmental factors are creating ever greater pressures for the efficient generation, transmission and use of energy. Materials developments are crucial to progress in all these areas: to innovation in design; to extending lifetime and maintenance intervals; and to successful operation in more demanding environments. Drawing together the broad community with interests in these areas, Energy Materials addresses materials needs in future energy generation, transmission, utilisation, conservation and storage. The journal covers thermal generation and gas turbines; renewable power (wind, wave, tidal, hydro, solar and geothermal); fuel cells (low and high temperature); materials issues relevant to biomass and biotechnology; nuclear power generation (fission and fusion); hydrogen generation and storage in the context of the 'hydrogen economy'; and the transmission and storage of the energy produced.

As well as publishing high-quality peer-reviewed research, Energy Materials promotes discussion of issues common to all sectors, through commissioned reviews and commentaries. The journal includes coverage of energy economics and policy, and broader social issues, since the political and legislative context influence research and investment decisions.

\section{CALL FOR PAPERS}

Contributions to the journal should be submitted online at http://ema.edmgr.com

To view the Notes for Contributors please visit: www.maney.co.uk/journals/notes/ema

Upon publication in 2006, this journal will be available via the Ingenta Connect journals service. To view free sample content online visit: www.ingentaconnect.com/content/maney

For further information please contact:

Maney Publishing UK

Tel: +44 (0)113 2497481 Fax: +44 (0)1132486983 Email: subscriptions@maney.co.uk

or

Maney Publishing North America

Tel (toll free): 8662975154 Fax: 6173546875 Email: maney@maneyusa.com

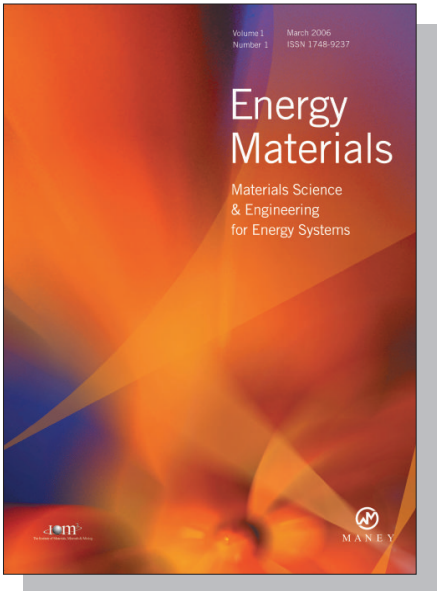

EDITORS

Dr Fujio Abe

NIMS, Japan

Dr John Hald, IPL-MPT, Technical University of Denmark, Denmark

Dr R Viswanathan, EPRI, USA

\section{SUBSCRIPTION INFORMATION}

Volume 1 (2006), 4 issues per year

Print ISSN: 1748-9237 Online ISSN: 1748-9245

Individual rate: $£ 76.00 / U S \$ 141.00$

Institutional rate: $£ 235.00 /$ US $\$ 435.00$

Online-only institutional rate: $£ 199.00 / U S \$ 367.00$

For special $\mathrm{IOM}^{3}$ member rates please email

subscriptions@maney.co.uk

\section{For further information or to subscribe online please visit www.maney.co.uk}



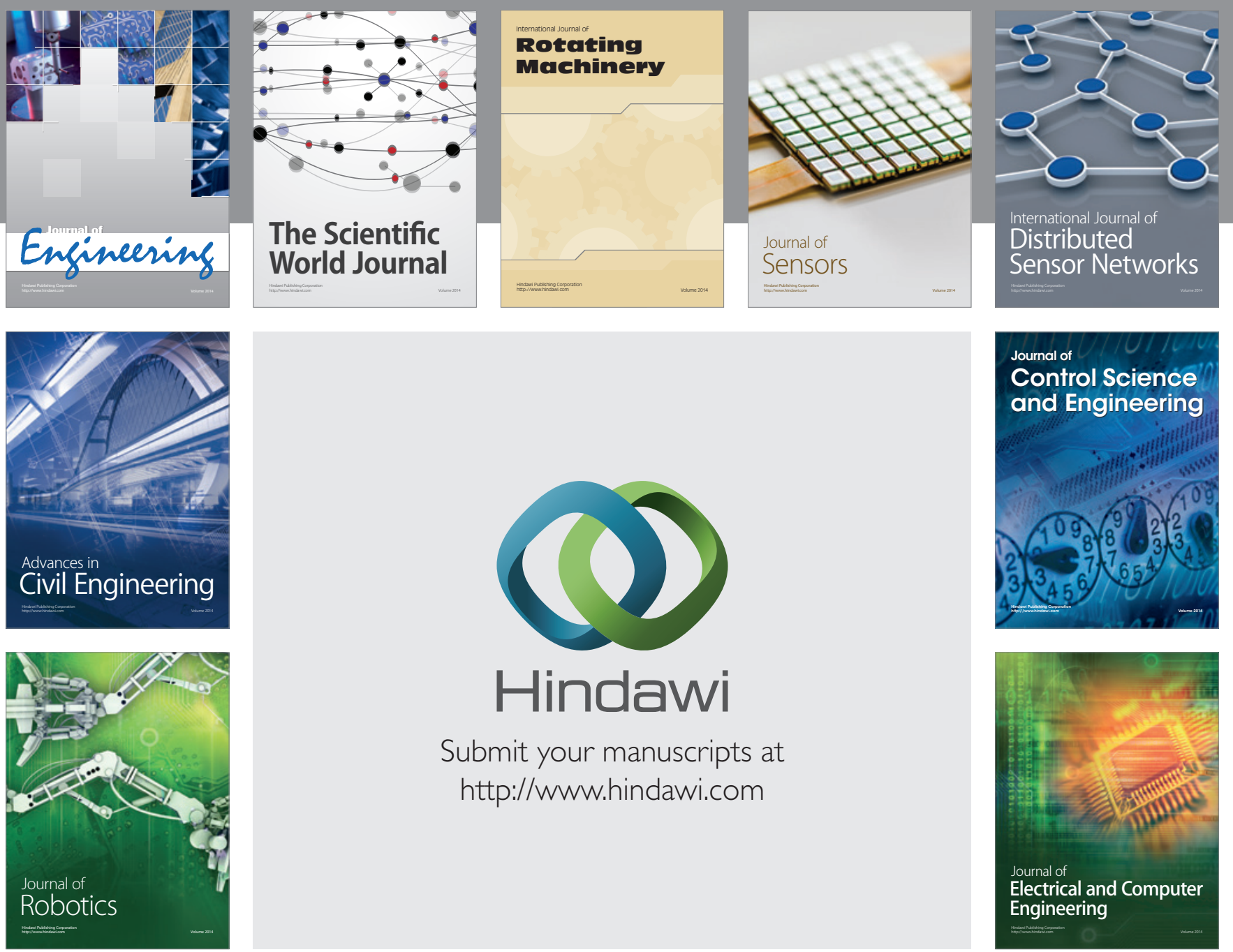

Submit your manuscripts at

http://www.hindawi.com
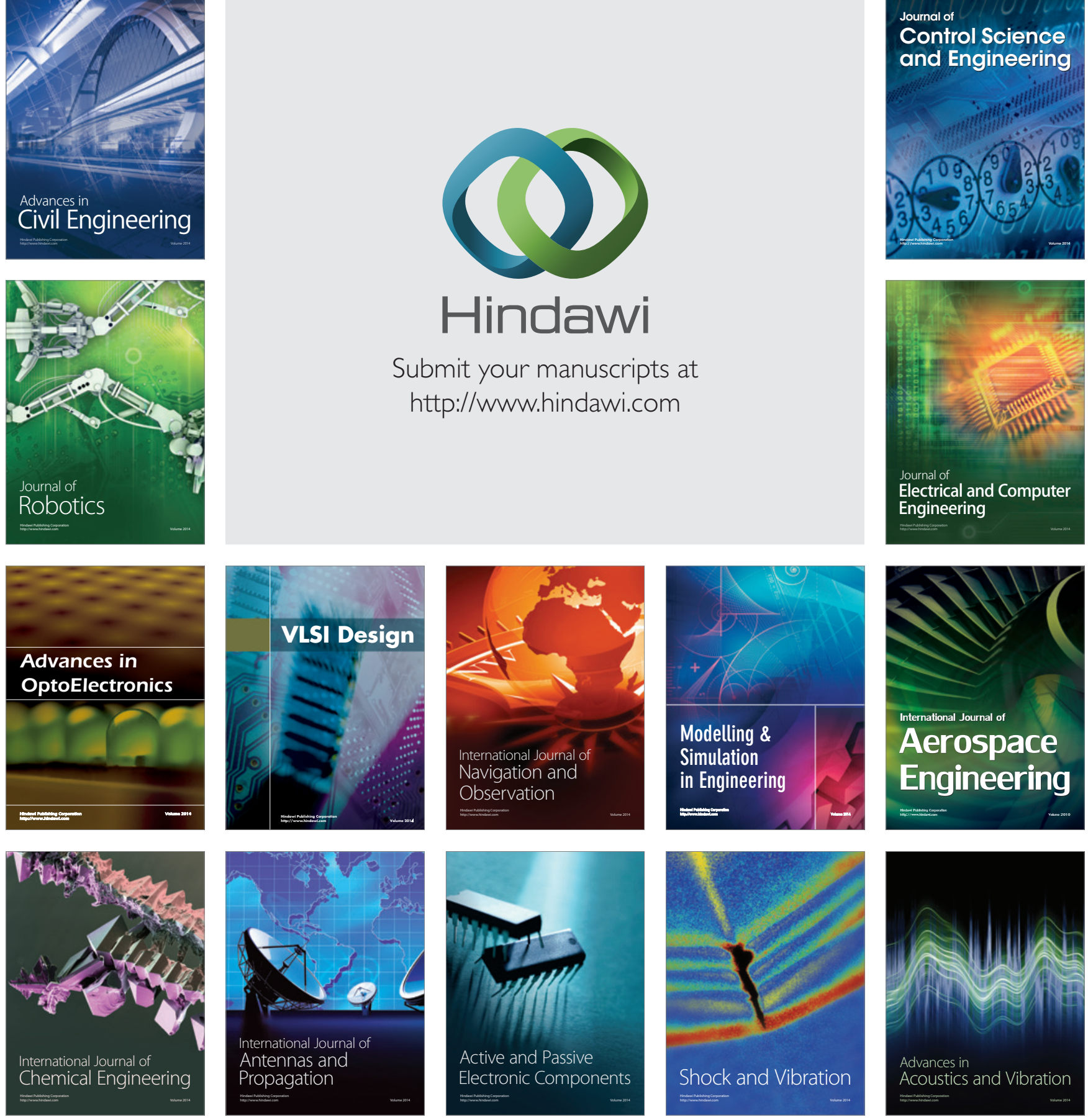